Please do not remove this page

RMIT

UNIVERSITY

\title{
Strain-rate sensitivity of die-cast magnesium-aluminium based alloys
}

ANG, Hua Qian; Zhu, Suming; Abbott, Trevor; Qiu, Dong; Easton, Mark

https://researchrepository.rmit.edu.au/esploro/outputs/9921860629001341/filesAndLinks?institution=61RMIT_INST\&index=null

ANG, H. Q., Zhu, S., Abbott, T., Qiu, D., \& Easton, M. (2017). Strain-rate sensitivity of die-cast magnesium-aluminium based alloys. Materials Science and Engineering A, 699, 239-246.

https://doi.org/10.1016/j.msea.2017.05.093

Document Version: Accepted Manuscript

Published Version: https://doi.org/10.1016/j.msea.2017.05.093

Repository homepage: https://researchrepository.rmit.edu.au

CC BY-NC-ND V4.0

(C) 2017 Elsevier B.V. All rights reserved.

Downloaded On 2023/04/26 22:14:14 +1000 


\title{
Strain-rate sensitivity of die-cast magnesium-aluminium based alloys
}

\author{
Hua Qian Anga , Suming Zhu ${ }^{\mathrm{a}}$, Trevor B. Abbott ${ }^{\mathrm{a}, \mathrm{b}}$, Dong Qiu ${ }^{\mathrm{a}}$, Mark A. Easton ${ }^{\mathrm{a}, *}$ \\ ${ }^{a}$ School of Engineering, RMIT University, Bundoora, Victoria 3083, Australia \\ ${ }^{b}$ Magontec Limited, Sydney, New South Wales 2000, Australia
}

\begin{abstract}
The strain-rate effect in die-cast magnesium-aluminium based alloys under quasi-static strain rates ranging from $10^{-6}$ to $10^{-1} \mathrm{~s}^{-1}$ was investigated. The strain-rate sensitivity was shown to decrease with increasing aluminium solute level in the matrix. Microstructural examination by electron backscattered diffraction (EBSD) revealed that deformation twinning is more active in the alloys with lower strain-rate sensitivity. It is suggested that the decrease in strain-rate sensitivity with increasing aluminium solute level is likely due to dynamic strain ageing from the interaction between aluminium solute and dislocations. The correlation between strain-rate sensitivity and ductility in AE44 is briefly discussed.
\end{abstract}

Keywords: Magnesium alloys; Strain-rate sensitivity; Dynamic strain ageing; Twinning; Diecasting

* Corresponding author. Tel: +61399256278

E-mail address: mark.easton@ rmit.edu.au 


\section{Introduction}

Magnesium ( $\mathrm{Mg}$ ) tends to show pronounced strain-rate sensitivity in mechanical testing due to the hexagonal close packed crystal structure [1]. Strain-rate sensitivity has been observed to be high in pure $\mathrm{Mg}$ [2] and strain-rate sensitivity decreases with increasing aluminium (Al) content in high-pressure die-cast $\mathrm{Mg}$-Al based alloys [2, 3]. The high strainrate sensitivity in high-pressure die-cast $\mathrm{Mg}$ alloys with lower $\mathrm{Al}$ content led to an increase in work hardening rate and tensile to yield ratio at higher strain rates, with a corresponding increase in energy absorption at higher strain rates [3]. Stanford et al. [4] showed that the strain-rate sensitivity of an extruded $\mathrm{Mg}-1 \mathrm{Al}$ alloy is $30 \%$ lower than that of pure $\mathrm{Mg}$ at $10^{-4}$ $10^{-1} \mathrm{~s}^{-1}$. The alloy was solution treated indicating that strain rate effect is also independent of processing conditions.

In contrast, Aune et al. [5] studied the behaviour of die-cast AM50 (Mg-5Al-0.3Mn, wt.\%), AM60 (Mg-6Al-0.3Mn) and AZ91 (Mg-9Al-1Zn) alloys at 15-130 s-1, but did not observe a significant variation in strain-rate sensitivity between the alloys despite a difference in $\mathrm{Al}$ content. This could be due to three factors. Firstly, they only investigated alloys with $\mathrm{Al}$ contents greater than $5 \mathrm{wt} . \%$ when the strain-rate sensitivity is relatively low. Secondly, their investigated strain rate range may be too small to see the effect of strain rate. Thirdly, the strain rates also fall in between quasi-static (typically $\left.<10^{0} \mathrm{~s}^{-1}\right)$ and dynamic $\left(\geq 10^{3} \mathrm{~s}^{-1}\right)$ domains. The latter two factors might be more plausible since Weiler and Wood [6] also reported no strain rate effect for sand-cast AE44 (Mg-4Al-4RE) in similar strain rate range $\left(100-300 \mathrm{~s}^{-1}\right)$. Research in this strain rate range, $10^{0}-10^{2} \mathrm{~s}^{-1}$, is uncommon due to experimental challenges.

At dynamic strain rates $\left(\geq 10^{3} \mathrm{~s}^{-1}\right)$, strain-rate sensitivity has been observed to increase with strain rate in mould cast Mg-9RE-4Zn [7], extruded $\mathrm{Mg}-8 \mathrm{Li}-1 \mathrm{Al}-1 \mathrm{Ce}$ [8] and die-cast $\mathrm{Mg}$-Al alloys $[9,10]$. At quasi-static strain rates $\left(<10^{0} \mathrm{~s}^{-1}\right)$, published results on the influence of strain rate on strain-rate sensitivity are ambiguous. A greater strain-rate sensitivity was revealed at strain rates below $10^{-4} \mathrm{~s}^{-1}$ and $10^{-5} \mathrm{~s}^{-1}$ for AZ31 (Mg-3Al-1Zn) [11] and pure $\mathrm{Mg}$ [12], respectively. Similarly, strain-rate sensitivity increased from 0.008 to 0.06 with decreasing strain rate from $10^{-3} \mathrm{~s}^{-1}$ to $10^{-9} \mathrm{~s}^{-1}$ for AZ31 [13]. However, this contrasts with the observations by Carlson [14] and $\mathrm{Gu}$ et al. [15], who showed no change in strain-rate sensitivity for die-cast AM60 at strain rates below $10^{0} \mathrm{~s}^{-1}$ and $10^{-2} \mathrm{~s}^{-1}$, respectively. Song et al. [16] tested three die-cast $\mathrm{Mg}$ alloys AM20 (Mg-2Al-0.3Mn), AM50 and AM60 in compression and observed little change in strain-rate sensitivity between $10^{-3}-10^{0} \mathrm{~s}^{-1}$.

It is clear that the published research is not completely regarding the effect of $\mathrm{Al}$ content on strain-rate sensitivity of $\mathrm{Mg}-\mathrm{Al}$ based alloys and how the strain-rate sensitivity changes with respect to strain rates, especially at quasi-static strain rates $\left(<10^{0} \mathrm{~s}^{-1}\right)$. The aim of this work is to measure the strain-rate sensitivity of various die-cast alloys and discern the governing mechanism behind the effect. For this purpose, the tensile behavior of commercial die-cast $\mathrm{Mg}$ alloys with various $\mathrm{Al}$ contents, i.e. AM40, AM60, AZ91 and AE44 were investigated over a wide strain rate range $10^{-6}-10^{-1} \mathrm{~s}^{-1}$. AM40 and AM60 are most commonly used in applications where energy absorption is required while AZ91 is widely used for some structural components of automobiles, aircraft, and computers, because of its good combination of mechanical properties and die-castability. AE44 was originally developed as 
a creep resistant alloy, but it has good combination of strength and ductility, especially after ageing [17], this makes it attractive for structural applications [18].

\section{Materials and Experimental Methods}

Commercial high-pressure die-cast AM40, AM60, AZ91 and AE44 alloys were used in this study. Details of the casting procedure can be found elsewhere [19]. Some AE44 specimens were given an ageing treatment at $200{ }^{\circ} \mathrm{C}$ for $32 \mathrm{~h}$ (T5), which produced significant age hardening as a result of precipitation of nanoscale Al-Mn particles [17]. The chemical compositions in wt.\% of these alloys analysed using inductively coupled plasma atomic emission spectroscopy (ICP-AES) are listed in Table 1.

Dog-bone-shaped cylindrical samples, $100 \mathrm{~mm}$ long with a $36 \mathrm{~mm}$ parallel section in the gauge length and a diameter of $5.6 \mathrm{~mm}$, were used in this study. Tensile tests were performed on an Instron 5569 Universal Testing Machine at room temperature using a constant rate of crosshead displacement with nominal strain rates in the range $10^{-6}-10^{-1} \mathrm{~s}^{-1}$. Each test was repeated three times.

Electron-backscattered diffraction (EBSD) data was collected in a FEI Nova NanoSEM at $20 \mathrm{kV}$ using a $0.5-\mu \mathrm{m}$ step size before and after tensile testing. Each sample was scanned three times, covering well over 500 grains. HKL Channel 5 Tango subroutine was used to quantify the area fraction of twinning. Five twinning systems were identified based on the misorientation angle/axis between twinned region and matrix. They are $\{10 \overline{1} 2\}$ twins (i.e. $86^{\circ}<12 \overline{1} 0>$ ), $\{10 \overline{1} 1\}$ twins (i.e. $56^{\circ}<12 \overline{1} 0>$ ), $\{10 \overline{1} 3\}$ twins (i.e. $64^{\circ}<12 \overline{1} 0>$ ), $\{10 \overline{1} 3\}-$ $\{10 \overline{1} 2\}$ twins (i.e. $22^{\circ}<12 \overline{1} 0>$ ) and $\{10 \overline{1} 1\}-\{10 \overline{1} 2\}$ twins (i.e. $38^{\circ}<12 \overline{1} 0>$ ) [20-22]. The Al solute concentration across grains was measured by energy dispersive X-ray (EDX) spectroscopy. At each sample location, a minimum of 150 points were taken in the $\alpha-\mathrm{Mg}$ matrix with a spacing of $0.1 \mu \mathrm{m}$ between each point using EDX line analysis. Three locations were analysed for each sample. The surfaces of all samples for EBSD and EDX analyses were prepared using standard mechanical polishing procedures and were finished by $0.06 \mu \mathrm{m}$ OP-S. The fracture surfaces were also investigated by a scanning electron microscopy (SEM) using secondary electron imaging.

\section{Results}

\subsection{Tensile Properties}

Figure 1 shows tensile flow curves at various strain rates, $\dot{\varepsilon}$ ranging from $10^{-6}$ to $10^{-1}$, for the as-cast AM40, AM60, AZ91 and AE44, together with the T5-treated AE44. The flow curves of AE44-T5 and as-cast AE44 consistently shift higher with increasing strain rate, and a substantial increase in the proof strength was observed. In contrast, the shift in flow curves of AM40 and AM60 is smaller but still visible, while the changes in flow curves of AZ91 are the barely observable.

The effects of strain rate on strength and ductility are shown in Figs. 2(a) and (b), respectively. In Fig. 2(a), 0.5\% proof strength is used because die-cast $\mathrm{Mg}$ alloys tend to 
show pronounced anelasticity and the $0.5 \%$ offset is a closer approximation to the $0.2 \%$ permanent plastic strain [23]. The $0.5 \%$ proof strength shows a more visible increase with strain rate for AE44 and AE44-T5 while the increase is moderate for AM40, AM60 and AZ91. It is noted that tensile strength appears to be less sensitive to strain rate and remains almost constant across strain rates for all alloys. This could be due to the fact that the present alloys do not reach necking and the tensile strength is the stress at fracture. Ductility appears to increase with decreasing strain rate in AE44, while the correlation of ductility with strain rate is less visible in AE44-T5, AM40 and AM60. Ductility appears to be independent of strain rate in AZ91.

\subsection{Strain Rate Sensitivity}

The differences in the levels of flow stress for different strain rates are indicative of strain-rate sensitivity, represented by $m=\frac{\delta \ln (\sigma)}{\delta \ln (\dot{\varepsilon})}[1,24,25]$. Figs. 3(a) and (b) show variations of strain-rate sensitivity with true strain and strain rate, respectively. Strain-rate sensitivity increases with strain in both AE44 and AE44-T5, while strain-rate sensitivity first decreases, passes through a minimum then increases again in AM40, AM60 and AZ91 alloys (Fig. 3(a)). In Fig. 3(b), strain-rate sensitivity appears to increase with decreasing strain rate in AE44 and AE44-T5, which is consistent with the observations from studies of pure $\mathrm{Mg}$ and other alloys [11-13]. There is no visible change in strain-rate sensitivity observed in AM40 and AZ91. There is, however, no consistent trend in AM60, where the strain-rate sensitivity exhibits a slight decrease, followed by a slight increase with decreasing strain rate. Since, the difference in strain-rate sensitivity is small, it could be assumed that there is no change in strain-rate sensitivity. Overall, AE44-T5 has the highest strain-rate sensitivity, followed by AE44, then AM40, AM60 and AZ91.

\subsection{Microstructural Characterization}

The deformation microstructure in tensile tested AE44, AM60, and AZ91 specimens at different strain rates was examined by EBSD (Fig. 4). The type of twins identified and the fraction of twinned area determined for these alloys are summarized in Table 2. While the starting microstructures (not shown) are twin-free, twins are formed after tensile deformation and the fraction of twinned area shows an increase with increasing strain rate, which is consistent with the previous studies [8, 26-28] on Mg alloys. Twinning is most active in AZ91, followed by AM60, and is least active in AE44 for a given strain rate.

Fig. 5 shows the fracture surfaces of AM60, AZ91 and AE44 after tensile testing at the highest and lowest strain rates. Overall, three types of fracture surfaces were observed: quasicleavage fracture in all AM60 samples and AE44 deformed at $10^{-5}-10^{-1} \mathrm{~s}^{-1}$, cleavage type of failure in AZ91 samples, and highly-dimpled ductile fracture in AE44 at $10^{-6} \mathrm{~s}^{-1}$. Both AM40 and AE44-T5 (not shown) exhibit similar quasi-cleavage fracture to the AM60 alloy, regardless of the applied strain rates. Cleavage fracture indicates brittle failure, typically controlled by the intermetallic phase [29] while highly-dimpled fracture surface indicates ductile fracture [30]. Quasi-cleavage fracture surface (Fig. 5(a), (b), (f)) normally contains cleavage planes $(\mathrm{P})$, small and shallow dimples $(\mathrm{S})$, along with some secondary cracks $(\mathrm{C})$ on the cleavage plane [31]. Cleavage fracture of AZ91 (Fig. 5(c) and (d)), shows the presence of 
shrinkage pores $(\mathrm{H})$ (circled) and some facets and steps $(\mathrm{F})$, correlating well with previous work [29]. The fracture surface of AE44 at $10^{-6} \mathrm{~s}-1$ (Fig. e) reveals significant amounts of small and large dimples (B), indicating ductile failure. In fact, AE44 at $10^{-6} \mathrm{~s}^{-1}$ shows the capability of accommodating large amounts of plastic strain, with ductility reaching almost $30 \%$ strain (Fig. 1(d)).

To provide an indicative distribution of $\mathrm{Al}$ solute in the $\alpha-\mathrm{Mg}$ grains, line profiles for $\mathrm{Al}$ solute concentration in the $\alpha-\mathrm{Mg}$ matrix were obtained by EDX as shown in Fig. 6 . The $\mathrm{Al}$ level at the centre and near grain boundaries are given in Table 3, together with the data predicted by Pandat ${ }^{\circledR}$ [32]. There is an increase in the concentration of $\mathrm{Al}$ in the $\alpha-\mathrm{Mg}$ towards the grain boundary as would be expected by non-equilibrium solidification with the grain boundary concentrations measured from EDX being between the eutectic concentrations predicted by the Equilibrium and Scheil-Gulliver equation, calculated by Pandat ${ }^{\circledR}[32]$, which is typically used for predicting solute and phase distributions in cast materials. This may indicate some solid state diffusion during the highly non-equilibrium conditions in high-pressure die-casting.

\section{Discussion}

The strain-rate sensitivity of $\mathrm{Mg}$-Al alloys has been reported to be affected by the alloying content of $\mathrm{Al}$ [3, 16, 33]. However, AM40 and AE44 have similar Al content in composition, but the strain-rate sensitivity of AE44 is significantly higher than AM40. Present results suggest that it is the Al solute level in the $\alpha$-Mg matrix that influences the strain-rate sensitivity rather than the overall $\mathrm{Al}$ content. Fig. 7(a) shows the inverse strain-rate sensitivity as a function of $\mathrm{Al}$ solute level in the $\mathrm{Mg}$ phase as measured by EDX. Although AE44 has similar overall Al content as AM40, AE44 has significantly lower Al solute in the $\alpha-\mathrm{Mg}$ matrix as most of the Al stays is in the form of Al-RE intermetallics [34-36].

The reduced strain-rate sensitivity with increasing Al solute concentration is considered to be related to dynamic strain ageing from the interaction of $\mathrm{Al}$ solute and dislocations. The dynamic strain ageing effect does not always manifest itself as serrations on stress-strain curves as reported previously [37, 38]. Diffusion of solute elements to dislocations tend to impede their motion [33, 37, 39, 40], leading to a strengthening effect. At higher strain rates the reduced time for diffusion diminishes this strengthening effect [41]. The solute effects, therefore, contribute a negative strain rate sensitivity component, however, in the absence of solute, magnesium has a positive strain rate sensitivity [1]. These two effects are combined in alloys with solute, to result in a lower overall strain rate sensitivity. Increasing Al solute concentration further enhances the dynamic strain ageing effect and reduces the strain-rate sensitivity. Dynamic strain ageing has been previously observed in cast AZ61 and AZ91 alloys due to interactions between $\mathrm{Al}$ solute atoms and mobile dislocations by Tahreen et al. [33].

Both AE44 and AE44-T5 have very little Al solute in the $\alpha$-Mg matrix, and hence they are less likely to be affected by dynamic strain ageing, especially in the T5 condition where even more solute is removed as a result of precipitation [17]. The net result is that the intrinsic strain-rate sensitivity in $\mathrm{Mg}$ which is often attributed to the hexagonal closed packed 
crystal structure [1] is manifested. This is further substantiated by Fig. 3(a). This monotonic increase of strain-rate sensitivity with strain in AE44 and AE44-T5 is the normal behaviour associated with the absence of dynamic strain againg while the initial decrease of strain-rate sensitivity in AM40, AM60 and AZ91 is a characteristic of dynamic strain ageing [37]. Both AE44 and AE44-T5 show higher strain-rate sensitivity at lower strain rates (Fig. 3(b)). The diminished influence of dynamic strain ageing in AE44 causes the strain-rate sensitivity behaviour to approach that of pure $\mathrm{Mg}$ [12].

When dynamic strain ageing takes effect, dislocation movement is restricted by solute and slip becomes more difficult [42]. Consequently other deformation modes such as twinning will be activated to accommodate plastic deformation. The increased twinning activity in the alloys with lower strain-rate sensitivity such as AZ91 is simply a concomitant effect of dynamic strain ageing due to the increased difficulty in slip.

Chun and Davies [27] reported negative strain-rate sensitivity in highly textured wrought AZ31 sheets and suggested that increasing twinning activity would reduce strain-rate sensitivity. As the present alloys have relatively low twinned area fraction and the permanent deformation is more likely to be slip-dominated, the observed differences in strain-rate sensitivity are not considered to be accounted for by twining activity even though the EBSD results seem to be consistent with the dependence of strain-rate sensitivity on twinning activity [27].

The dynamic strain ageing mechanism also provides an alternative explanation for the reported influence of section thickness on strain-rate sensitivity of die-cast AM60 by Gu et al. [15]. They attributed the higher strain-rate sensitivity in the thinner specimen (1.3 mm-thick) to the finer grain size resulting from the faster cooling rate. It might be true that decreasing grain size increases the strain-rate sensitivity, as demonstrated by Figueiredo et al. [12] on pure $\mathrm{Mg}$, however, faster cooling rates also reduce the solute level due to reduced back diffusion during solidification [43]. This is because in non-equilibrium cooling, the microstructure consists of proeutectic $\alpha$, eutectic $\alpha$ (supersaturated solid solution), and eutectic $\beta$. The higher the deviation from equilibrium conditions, the higher the shift of the effective (non-equilibrium) solidus line from the theoretical line. Because of the fast cooling rate in die-casting, the solidus line shifts considerably, leading to a higher amount of eutectic $\beta$ on the grain boundaries, and a lower amount of aluminium in solid solution [44]. The lowered solute concentration would reduce dynamic strain ageing, leading to higher strainrate sensitivity for the faster cooled section. Fig. 7(b) shows three similar die-cast AM60 alloy specimens with a variation in strain-rate sensitivity. The increased strain-rate sensitivity in thinner AM60 specimens is more likely due to a lower Al solute concentration. It should be pointed out that present specimens are cylindrical with a $5.6 \mathrm{~mm}$-diameter, and might have a cooling rate in between the $1.3 \mathrm{~mm}$ and $6.5 \mathrm{~mm}$-thick flat specimens.

Finally, it is worth briefly discussing the effect of strain-rate sensitivity on tensile ductility (Fig. 2(b)). AE44 with the high strain-rate sensitivity shows larger reduction in ductility and the fracture mode changed from ductile fracture at $10^{-6} \mathrm{~s}^{-1}$ to quasi-cleavage fracture at $10^{-1} \mathrm{~s}^{-1}$. Present results, and results from literature $[3,16]$ have shown that strainrate sensitivity of die-cast $\mathrm{Mg}$ alloys is manifest as an increase in work hardening rate. The higher work hardening rate at $10^{-1} \mathrm{~s}^{-1}$ in AE44 suggests increasing difficulty for dislocations to slip. This could be due to insufficient time for cross-slip or climb of dislocations, leading 
to more dislocation pile-ups at grain boundaries at higher strain rates [39], in turn lowering the ductility. While there may be a correlation between strain-rate sensitivity and ductility in AE44, the more brittle fracture of AZ91 is mostly a consequence of the hard and brittle percolating network of $\mathrm{Mg}_{17} \mathrm{Al}_{12}$ which is abundant and continuous throughout the microstructure, and cracks could easily propagate throughout the material, leading to early fracture [45]. Consequently, ductility is not dependant on strain rate in AZ91.

\section{Conclusions}

This study has investigated the strain-rate sensitivity in commercial die-cast $\mathrm{Mg}$ alloys AM40, AM60, AZ91 and AE44 over a wide strain rate range $10^{-6}-10^{-1} \mathrm{~s}^{-1}$. It is shown that it is the $\mathrm{Al}$ solute level in the $\mathrm{Mg}$ matrix, rather than the $\mathrm{Al}$ content in the alloys in general, that affects the strain-rate sensitivity. The decrease in strain-rate sensitivity with increasing Al solute level is likely related to dynamic strain ageing from the interaction of Al solute with dislocations. The deformation twinning is more active in the alloys with lower strain-rate sensitivity as a result of restricted slip from dynamic strain ageing. The high strain-rate sensitivity in AE44, manifest as an increase in work hardening rate, suggests difficulty in dislocation motion at higher strain rates, reducing the ductility.

\section{Acknowledgements}

This work was supported by the Australian Research Council [Grant number LP130100828]. The authors would like to thank Dr. Chengfan Gu, Dr. Matthew Field, Mr. Carmelo Todaro and Mr. Peter Rummel for their technical assistance and acknowledge the use of the RMIT Microscopy and Microanalysis Facility. The authors would also like to thank Dr. Carlos Cáceres from the University of Queensland for his helpful comments on the manuscript 


\section{References}

[1] M.A. Meyers, Dynamic Behaviour of Materials, John Wiley \& Sons, New York, 1994.

[2] C.A. Newland, M.T. Murray, Strain rate dependent behaviour of magnesium-based alloys, in: Proceedings of the First Australasian Congress on Applied Mechanics, Institution of Engineers, Australia, 1996, pp. 73-76.

[3] T.B. Abbott, M.A. Easton, R. Schmidt, Magnesium for crashworthy components, in: M. Byko (Ed.), Journal of The Minerals, Metals, and Materials Society, TMS Annual Meeting, California, 2003, pp. 227-230.

[4] N. Stanford, M.R. Barnett, Effect of Al and Gd solutes on the strain rate sensitivity of magnesium alloys, Metall. Mater. Trans. A 41 (2010) 734-743.

[5] T.K. Aune, D. Albright, H. Westengen, T.E. Johnsen, B. Anderson, Behavior of die cast magnesium alloys subject to rapid deformation, SAE Technical Paper, 2000 pp. 200001-1116.

[6] J.P. Weiler, J.T. Wood, Strain-rate effects of sand-cast and die-cast magnesium alloys under compressive loading, in: S.N. Mathaudhu, W.H. Sillekens, N.R. Neelameggham, N. Hort (Eds.), Magnesium Technology 2012, John Wiley \& Sons, Florida, 2012, pp. 365-370.

[7] Z. Leng, H.J. Pan, Z.Y. Niu, C.H. Guo, Q. Zhang, Y.P. Chang, et al., Mechanical behavior, deformation and damage mechanisms of $\mathrm{Mg}-\mathrm{RY}-\mathrm{Zn}$ alloy under high strain rate, Mater. Sci. Eng. A 651 (2016) 336-340.

[8] C.H. Guo, F.C. Jiang, R.Z. Wu, M.L. Zhang, Effect of strain rate on compressive mechanical properties of extruded Mg-8Li-1Al-1Ce alloy, Mater. Des. 49 (2013) 110115.

[9] H. Asgari, J.A. Szpunar, A.G. Odeshi, Texture evolution and dynamic mechanical behavior of cast AZ magnesium alloys under high strain rate compressive loading, Mater. Des. 61 (2014) 26-34.

[10] I.R. Ahmad, D.W. Shu, Tensile properties of die-cast magnesium alloy AZ91D at high strain rates in the range between $300 \mathrm{~s}^{-1}$ and $1500 \mathrm{~s}^{-1}$, in: Applied Mechanics and Materials, Trans Tech Pub., Switzerland, 2010, pp. 325-330.

[11] X.Z. Lin, D.L. Chen, Strain hardening and strain-rate sensitivity of an extruded magnesium alloy, J. Mater. Eng. Perform. 17 (2008). 894-901.

[12] R.B. Figueiredo, F. Poggiali, C. Silva, P.R. Cetlin, T.G. Langdon, The influence of grain size and strain rate on the mechanical behavior of pure magnesium, J. Mater. Sci. 51 (2016). 3012-3024.

[13] T. Matsunaga, H. Somekawa, H. Hongo, M. Tabuchi, Deformation mechanism transition with strain rate in $\mathrm{Mg}-3 \mathrm{Al}-1 \mathrm{Zn}$ alloy at room temperature, Mater. Sci. Eng. A 647 (2015) 212-215.

[14] B.E. Carlson, The effect of strain rate and temperature on the deformation of die cast AM60B, SAE Technical Paper, 1995 pp.950425.

[15] G.Y. Gu, S.T. Lin, Y. Xia, Q. Zhou, Experimental study on influence of section thickness on mechanical behavior of die-cast AM60 magnesium alloy, Mater. Des. 38 (2012). 124-132.

[16] W.Q. Song, P. Beggs, M.A. Easton, Compressive strain-rate sensitivity of magnesiumaluminum die casting alloys, Mater. Des. 30 (2009). 642-648.

[17] S.M. Zhu, T.B. Abbott, M.A. Gibson, J.F. Nie, M.A. Easton, Age hardening in die-cast Mg-Al-RE alloys due to minor Mn additions, Mater. Sci. Eng. A 656 (2016) 34-38. 
[18] P. Bakke, K. Pettersen, H. Westengen, Improving the strength and ductility of magnesium die-casting alloys via rare-earth addition, J. Miner. Met. Mater. Soc. 55 (2003). 46-51.

[19] A.V. Nagasekhar, M.A. Easton, C.H. Cáceres, Solute content and the grain microstructure of high pressure die cast magnesium-aluminium alloys, Adv. Eng. Mater. 11 (2009). 912-919.

[20] C.S. Roberts, Magnesium and its Alloys, John Wiley \& Sons, New York, 1960.

[21] B.C. Wonsiewicz, W.A. Backofen, Independent slip systems and ductility of hexagonal polycrystals, Trans. Metall. Soc. AIME 239 (1967) 1422-1433.

[22] M.D. Nave, M.R. Barnett, Microstructures and textures of pure magnesium deformed in plane-strain compression, Scr. Mater. 51 (2004). 881-885.

[23] H.Q. Ang, T.B. Abbott, S.M. Zhu, C.F. Gu, M.A. Easton, Proof stress measurement of die-cast magnesium alloys, Mater. Des. 112 (2016) 402-409.

[24] E. Karimi, A. Zarei-Hanzaki, M.H. Pishbin, H.R. Abedi, P. Changizian, Instantaneous strain rate sensitivity of wrought AZ31 magnesium alloy, Mater. Des. 49 (2013) 173180.

[25] W.S. Lee, T.H. Chen, Rate-dependent deformation and dislocation substructure of AlSc alloy, Scr. Mater. 54 (2006) 1463-1468.

[26] C.M. Cepeda-Jiménez, J.M. Molina-Aldareguia, M.T. Pérez-Prado, Origin of the twinning to slip transition with grain size refinement, with decreasing strain rate and with increasing temperature in magnesium, Acta Mater. 88 (2015) 232-244.

[27] Y.B. Chun, C. Davies, Twinning-induced negative strain rate sensitivity in wrought $\mathrm{Mg}$ alloy AZ31, Mater. Sci. Eng. A 528 (2011) 5713-5722.

[28] J.W. Liu, D. Chen, Z.H. Chen, H.G. Yan, Deformation behavior of AZ31 magnesium alloy during tension at moderate temperatures, J. Mater. Eng. Perform. 18 (2009) 966972.

[29] D.G.L Prakash, D. Regener, W.J.J Vorster, Microscopic failure modes of hpdc AZ91HP magnesium alloy under monotonic loading, Mater. Sci. Eng. A 488 (2008) 303-310.

[30] J. Song, S.M. Xiong, M. Li, J. Allison, In situ observation of tensile deformation of high-pressure die-cast specimens of AM50 alloy, Mater. Sci. Eng. A 520 (2009) 197201.

[31] S.G. Lee, G.R. Patel, A.M. Gokhale, A. Sreeranganathan, M.F. Horstemeyer, Quantitative fractographic analysis of variability in the tensile ductility of high-pressure die-cast AE44 Mg-alloy, Mater. Sci. Eng. A 427 (2006) 255-262.

[32] W. Cao, S.L. Chen, F. Zhang, K. Wu, Y. Yang, Y.A. Chang, et al., PANDAT software with PanEngine, PanOptimizer and PanPrecipitation for multi-component phase diagram calculation and materials property simulation, Calphad 33 (2009) 328-342.

[33] N. Tahreen, D.L. Chen, M. Nouri, D.Y. Li, Effects of aluminum content and strain rate on strain hardening behavior of cast magnesium alloys during compression, Mater.Sci.Eng. A 594(2014) 235-245.

[34] S.M. Zhu, J.F. Nie, M.A. Gibson, M.A. Easton, P. Bakke, Microstructure and creep behavior of high-pressure die-cast magnesium alloy AE44, Metall. Mater. Trans. A 43 (2012) 4137-4144.

[35] S.M. Zhu, M.A. Easton, T.B. Abbott, M.A. Gibson, J.F. Nie, The influence of individual rare earth elements ( $\mathrm{La}, \mathrm{Ce}$, or $\mathrm{Nd}$ ) on creep resistance of die-cast magnesium alloy AE44, Adv. Eng. Mater. 18 (2016) 932-937.

[36] M.I. Khan, A.O. Mostafa, M. Aljarrah, E. Essadiqi, M. Medraj, Influence of cooling rate on microsegregation behavior of magnesium alloys, J. Mater. (2014) 1-18.

[37] L.P. Kubin, Y. Estrin, Dynamic strain ageing and the mechanical response of alloys, J. Phys. III 1 (1991) 929-943. 
[38] L. Jiang, J.J. Jonas, R. Mishra, Effect of dynamic strain aging on the appearance of the rare earth texture component in magnesium alloys, Mater. Sci. Eng. A 528 (2011) 65966605.

[39] A. Van den Beukel, Theory of the effect of dynamic strain aging on mechanical properties, Phys. Stat. Sol. (a) 30 (1975) 197-206.

[40] Z. Trojanová, P. Lukác, K.U. Kainer, V. Gärtnerová, Dynamic strain ageing during stress relaxation in selected magnesium alloys containing rare earth elements, Adv. Eng. Mater. 7 (2005) 1027-1032.

[41] G. Rajaram, S. Kumaran, S. Suwas, Effect of strain rate on tensile and compression behaviour of Al-Si/graphite composite, Mater. Sci. Eng. A 528 (2011) 6271-6278.

[42] W.D. Callister, D.G. Rethwisch, Materials Science and Engineering: An Introduction, seventh ed., John Wiley \& Sons, New York, 2007.

[43] W. Kurz, D.J. Fisher, Fundamentals of Solidification, fourth ed., Trans Tech Pub., Switzerland, 1998.

[44] S. Spigarelli, M. Regev, E. Evangelista, A. Rosen, Review of creep behaviour of AZ91 magnesium alloy produced by different technologies, Mater. Sci. Tech. 17 (2001) 627638.

[45] B. Zhang, A.V. Nagasekhar, T. Sivarupan, C.H. Cáceres, Deformation behavior of the percolating intermetallic microstructure of high pressure die cast AZ91 alloy, Adv. Eng. Mater. 15 (2013) 1059-1067. 
Table 1. Chemical compositions (wt.\%) determined by inductively coupled plasma atomic emission spectroscopy (ICP-AES) for the studied die-cast Mg alloys.

\begin{tabular}{cccccc}
\hline Alloy & Al & Mn & RE $($ Ce+La $)$ & Zn & Mg \\
\hline AM40 & 4.44 & 0.21 & $<0.01$ & 0.05 & Bal. \\
AM60 & 6.26 & 0.29 & $<0.01$ & 0.1 & Bal. \\
AZ91 & 8.88 & 0.19 & $<0.01$ & 0.74 & Bal. \\
AE44 & 3.67 & 0.31 & 3.83 & $<0.01$ & Bal. \\
\hline
\end{tabular}


Table 2. The type of twins formed in the tensile tested specimens and the fraction of twinned area determined by EBSD mapping.

\begin{tabular}{cccccccc}
\hline \multirow{2}{*}{ Alloy } & $\begin{array}{c}\text { Strain } \\
\text { rate }\end{array}$ & \multicolumn{5}{c}{ Twinned area fraction (\%) \pm standard deviations } & Total \\
\cline { 3 - 7 } & $\left(\mathbf{s}^{-1}\right)$ & $\{10 \overline{1} 2\}$ & $\{10 \overline{1} 1\}$ & $\{10 \overline{1} 3\}$ & $\{10 \overline{1} 3\}-$ & $\{10 \overline{1} 1\}-$ & twinned area \\
& & & & $\{10 \overline{1} 2\}$ & $\{10 \overline{1} 2\}$ & fraction (\%) \\
\hline \multirow{2}{*}{ AE44 } & $10^{-6}$ & $0.50 \pm 0.19$ & $0.19 \pm 0.09$ & & ${ }^{*} \mathrm{n} / \mathrm{a}$ & & $0.69 \pm 0.24$ \\
& $10^{-3}$ & $1.61 \pm 0.13$ & $0.39 \pm 0.01$ & $0.24 \pm 0.16$ & ${ }^{*} \mathrm{n} / \mathrm{a}$ & $0.05 \pm 0.07$ & $2.29 \pm 0.23$ \\
& $10^{-1}$ & $2.65 \pm 0.42$ & $0.31 \pm 0.02$ & $0.26 \pm 0.06$ & $0.06 \pm 0.10$ & $0.10 \pm 0.08$ & $3.38 \pm 0.37$ \\
\hline \multirow{2}{*}{ AM60 } & $10^{-6}$ & $1.43 \pm 0.17$ & $0.20 \pm 0.05$ & $0.21 \pm 0.05$ & $0.14 \pm 0.02$ & $0.11 \pm 0.10$ & $2.10 \pm 0.34$ \\
& $10^{-3}$ & $3.68 \pm 0.46$ & $0.58 \pm 0.02$ & $0.27 \pm 0.10$ & $0.15 \pm 0.02$ & $0.15 \pm 0.06$ & $4.84 \pm 0.45$ \\
& $10^{-1}$ & $4.57 \pm 0.50$ & $0.47 \pm 0.22$ & $0.16 \pm 0.05$ & $0.21 \pm 0.14$ & $0.33 \pm 0.12$ & $5.80 \pm 0.56$ \\
\hline \multirow{2}{*}{ AZ91 } & $10^{-6}$ & $5.95 \pm 0.32$ & $0.44 \pm 0.04$ & $0.31 \pm 0.08$ & $0.02 \pm 0.001$ & $0.08 \pm 0.02$ & $6.81 \pm 0.19$ \\
& $10^{-2}$ & $6.40 \pm 0.11$ & $0.39 \pm 0.03$ & $0.16 \pm 0.03$ & $0.13 \pm 0.12$ & $0.21 \pm 0.05$ & $7.31 \pm 0.17$ \\
\hline
\end{tabular}

${ }^{*}$ Undetected due to insignificant amount 
Table 3. Comparison of $\mathrm{Al}$ solute concentration (wt.\%) in the $\alpha-\mathrm{Mg}$ matrix obtained by EDX and Pandat ${ }^{\circledR}$.

\begin{tabular}{cccccc}
\hline & \multicolumn{5}{c}{ Al solute concentration (wt.\%) in $\boldsymbol{\alpha - M g}$ matrix } \\
\cline { 2 - 6 } Alloy & \multicolumn{2}{c}{ EDX } & \multicolumn{3}{c}{ Pandat ${ }^{\circledR}$ [32] } \\
\cline { 2 - 6 } & Centre & Boundaries & $\begin{array}{c}\text { Initial } \\
\text { Concentration }\end{array}$ & $\begin{array}{c}\text { Solidus } \\
\text { (Equilibrium) }\end{array}$ & Solidus (Scheil) \\
\hline AM40 & 2.7 & $4-5$ & 1.3 & 3.9 & 12.5 \\
AM60 & 3.4 & $8-10$ & 1.8 & 5.8 & 12.5 \\
AZ91 & 6.5 & $7-15$ & 2.7 & 8.7 & 2.7 (46.5 wt.\% Zn) \\
AE44 & 1.7 & $2-4$ & 1.2 & 2.5 & 12.5 \\
AE44-T5 & 1.3 & $2-3$ & $n$ & & $"$ \\
\hline
\end{tabular}



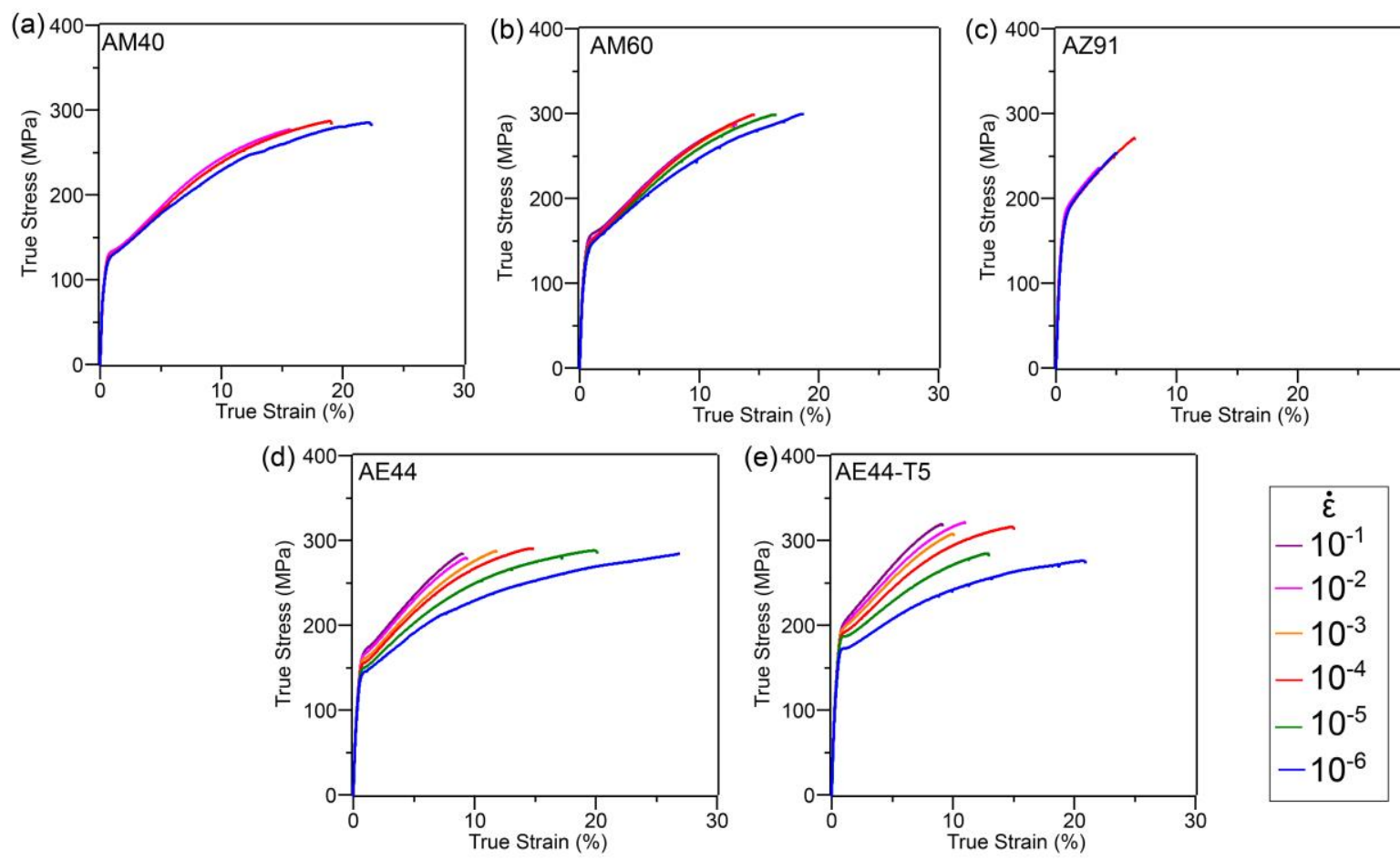

Fig. 1. True stress-strain curves of as-cast (a) AM40, (b) AM60, (c) AZ91, (d) AE44 and T5aged (e) AE44 at different nominal strain rates, $\dot{\varepsilon}$. 

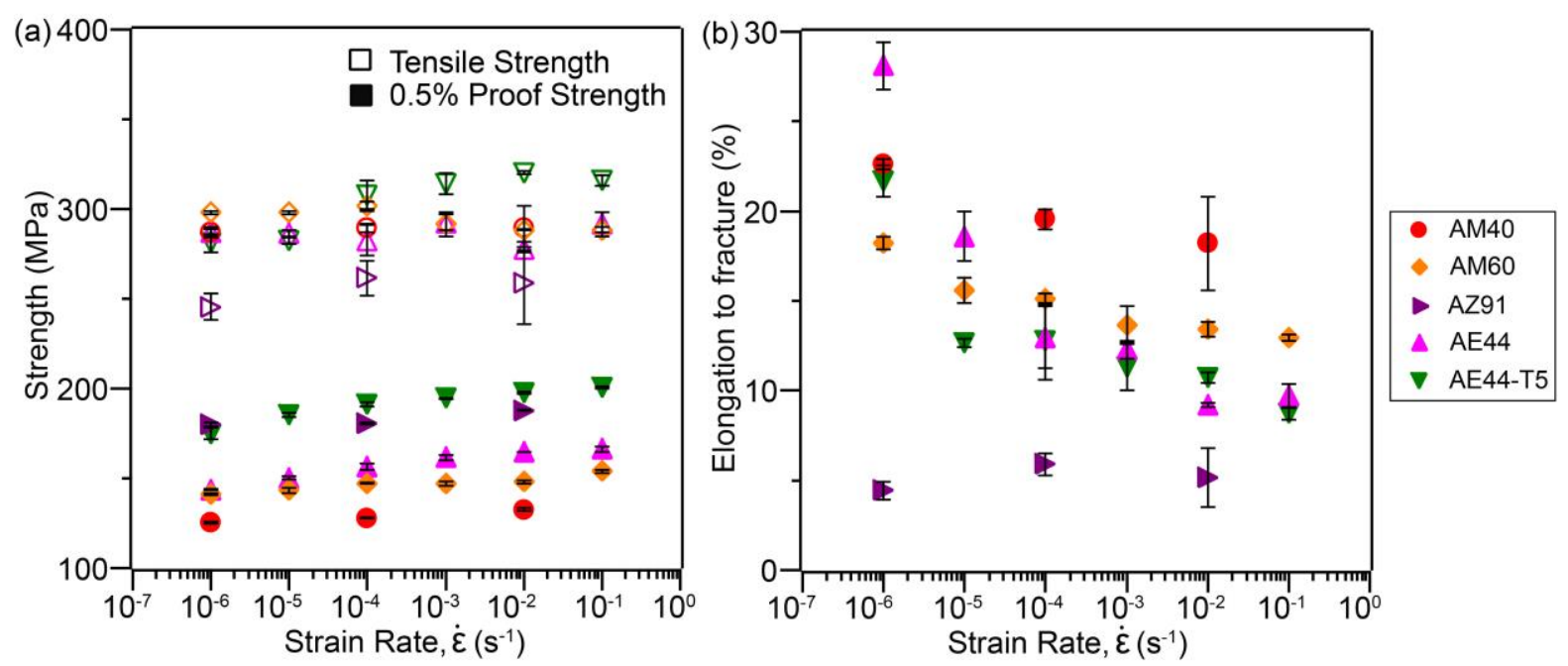

Fig. 2. Effects of strain rate on (a) strength (MPa) and (b) elongation to fracture (\%) of ascast AM40, AM60, AZ91, AE44 and T5-aged AE44. The solid and empty filled symbols in (a) indicate the $0.5 \%$ proof strength and tensile strength, respectively. 

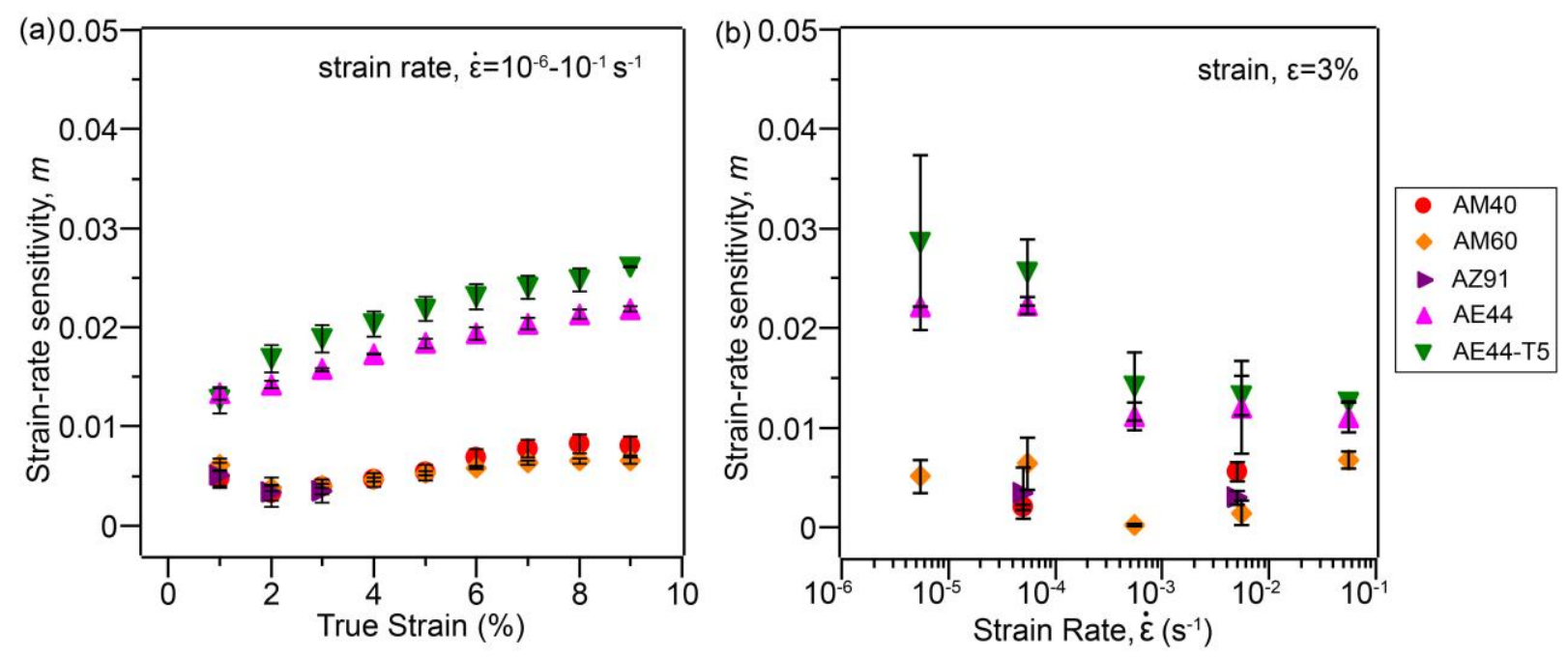

Fig. 3. Variations of strain-rate sensitivity with (a) true strain, covering strain rates, $\dot{\varepsilon}$ from $10^{-6}-10^{-1} \mathrm{~s}^{-1}$ and (b) with strain rate at $3 \%$ strain. The strain rate in (b) corresponds to the average of the upper and lower values. 


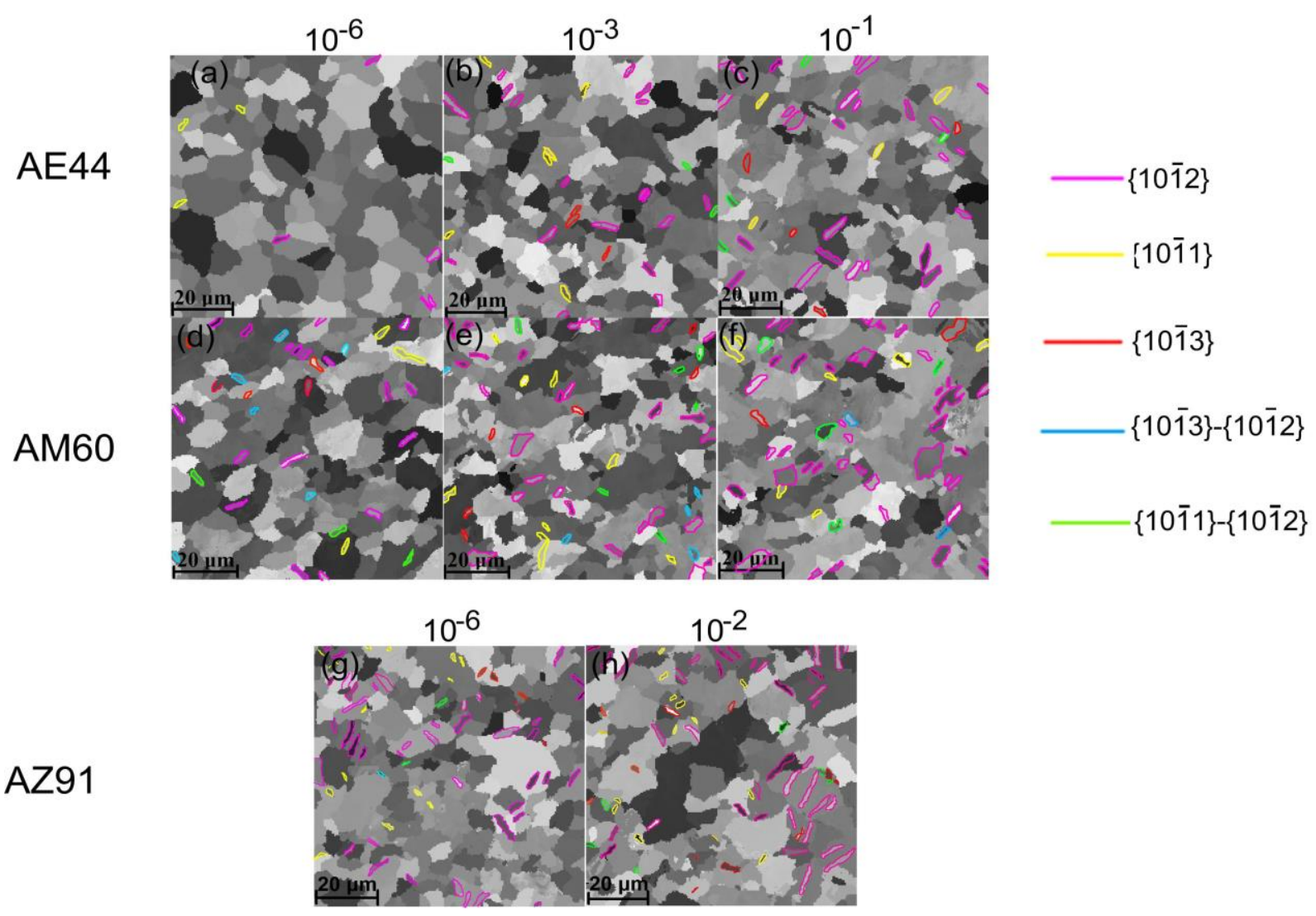

Fig. 4. EBSD maps showing formation of different types of twins in as-cast AE44, AM60, and AZ91 specimens after tensile testing at different strain rates. The loading direction is horizontal. Note that the highest strain rate tested for AZ91 is $10^{-2} \mathrm{~s}^{-1}$. 


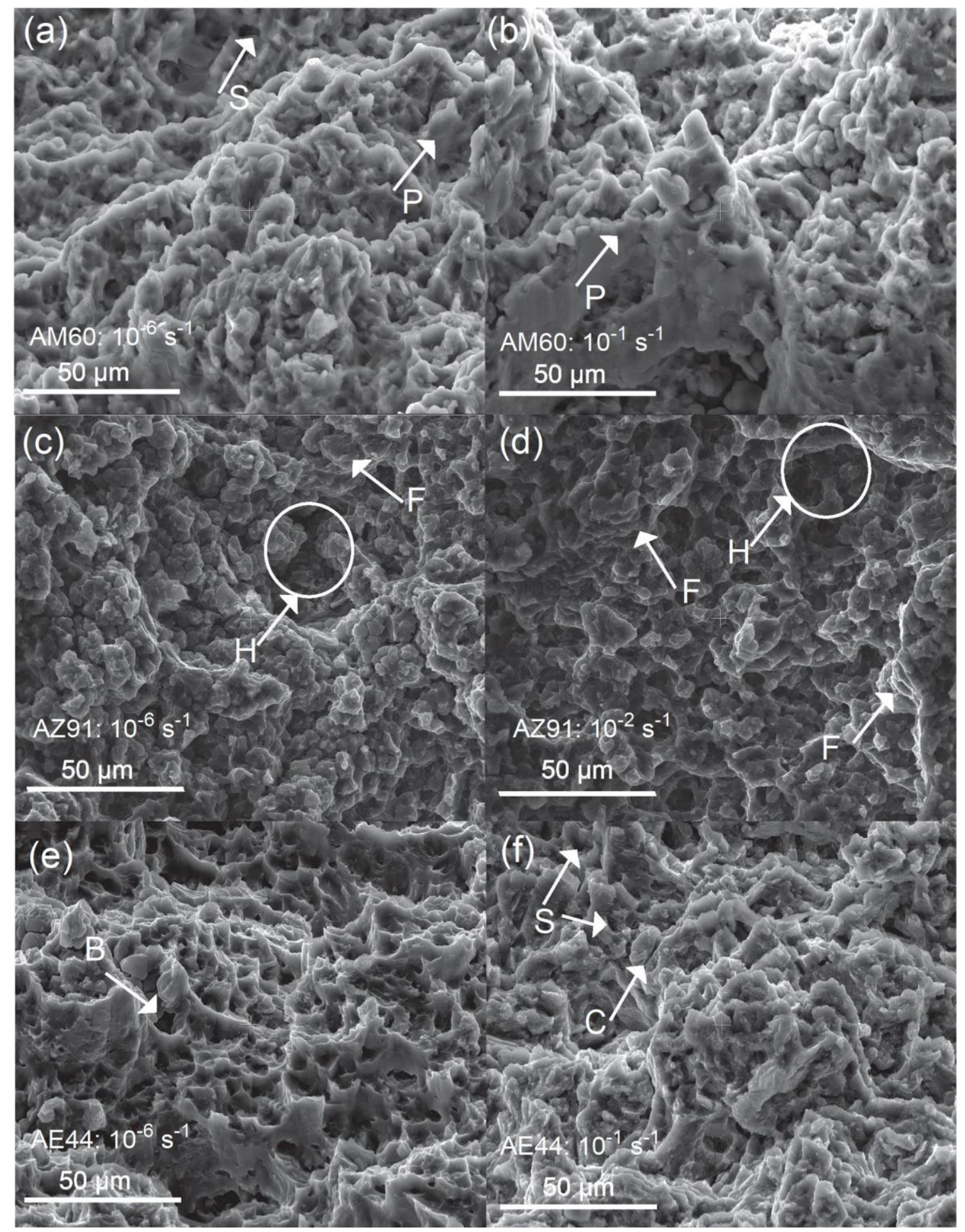

Fig. 5. Secondary electron images of fracture surfaces of (a, b) AM60, (c, d) AZ91 and (e, f) AE44 at different strain rates, showing different features of fracture, such as cleavage plane $(\mathrm{P})$, shrinkage pores $(\mathrm{H})$, facets and steps $(\mathrm{F})$, secondary cracks $(\mathrm{C})$, large dimple $(\mathrm{B})$ and small dimple (S). 

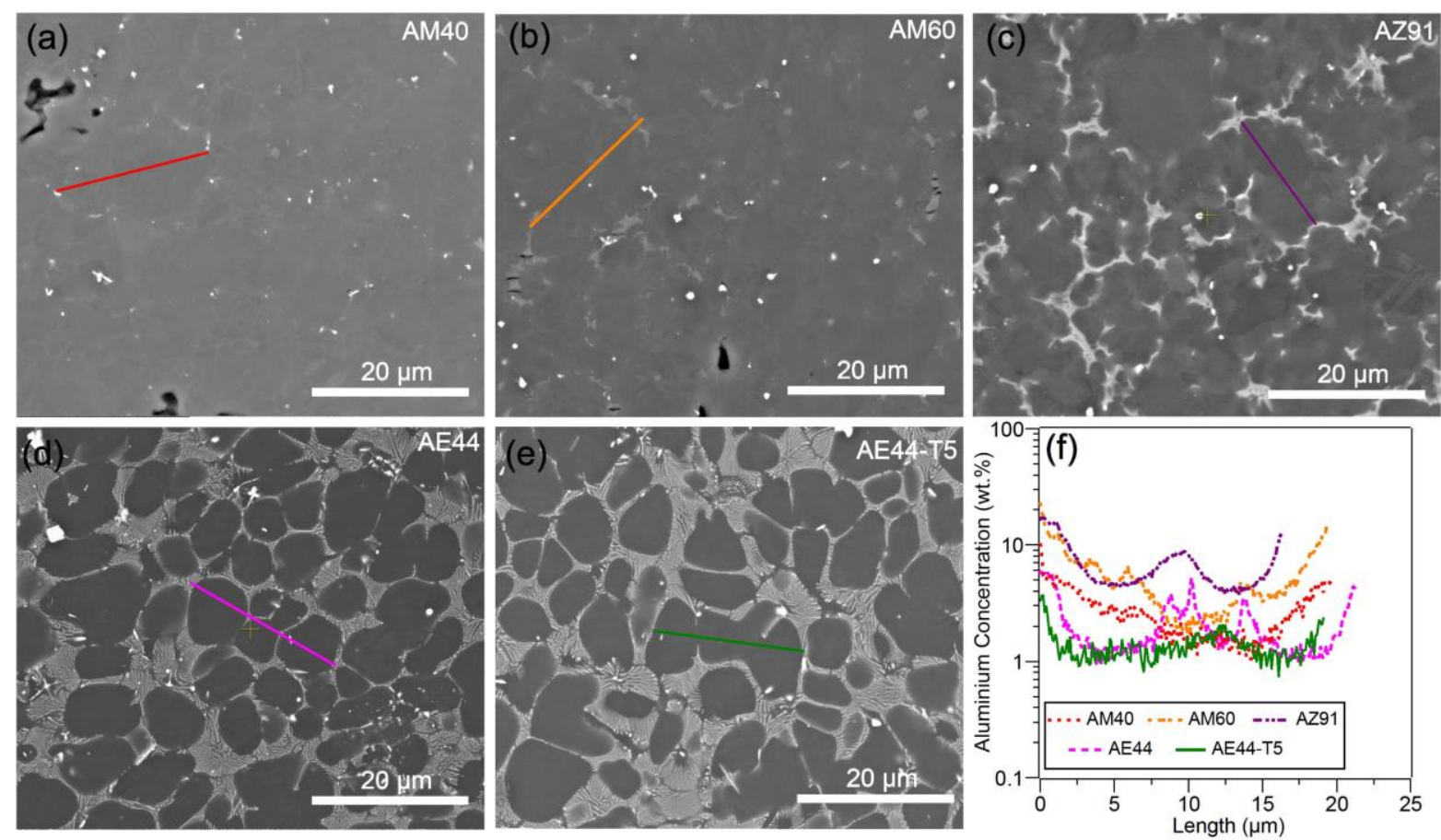

Fig. 6. Backscattered electron images and EDX line profiles of the $\alpha-\mathrm{Mg}$ matrix in (a) AM40, (b) AM60, (c) AZ91, (d) AE44, and (e) AE44-T5. The Al concentration (wt.\%) across the regions indicated in the SEM micrographs is shown in (f). There is an increase in the $\mathrm{Al}$ concentration from the centre of the dendrite cells towards the boundaries. 

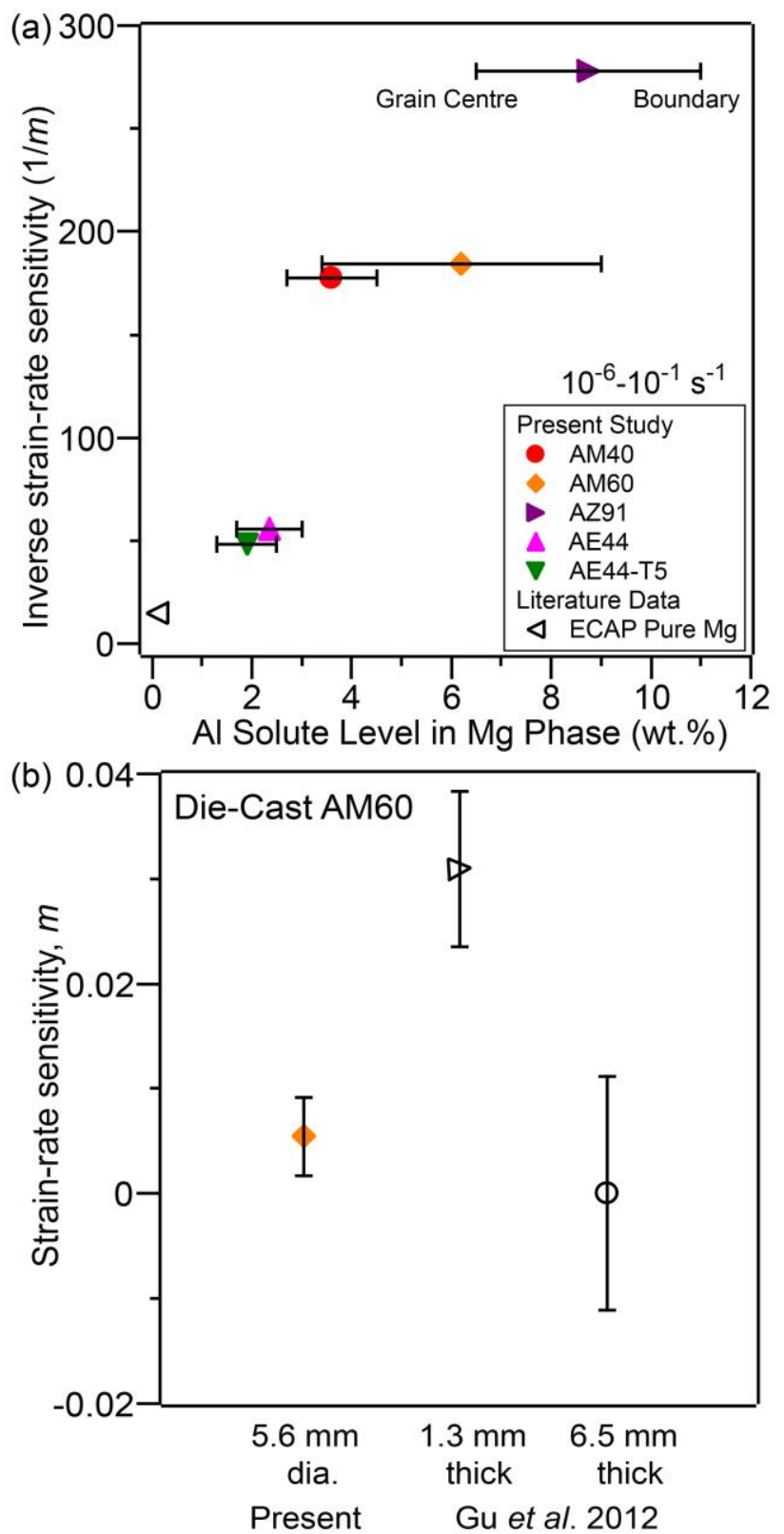

Fig. 7. A correlation of strain-rate sensitivity and Al solute concentration: (a) Inverse strainrate sensitivity versus $\mathrm{Al}$ solute level in $\mathrm{Mg}$ phase and (b) strain-rate sensitivity as a function of sample diameter and thicknesses in die-cast AM60. Strain-rate sensitivity of pure Mg [12] and die-cast AM60 [15] taken from literature data are included. Strain-rate sensitivity represents an average for strain rates range $10^{-6}-10^{-1} \mathrm{~s}^{-1}$. 